\title{
p75 neurotrophin receptor mediates apoptosis in transit-amplifying cells and its overexpression restores cell death in psoriatic keratinocytes
}

\author{
F Truzzi ${ }^{1,3}$, A Marconi ${ }^{1,3}$, P Atzei $^{1}$, MC Panza ${ }^{1}$, R Lotti ${ }^{1}$, K Dallaglio $^{1}$, R Tiberio ${ }^{2}$, E Palazzo ${ }^{1}$, C Vaschieri ${ }^{1}$ and C Pincelli*,1
}

p75 neurotrophin receptor (p75NTR) belongs to the TNF-receptor superfamily and signals apoptosis in many cell settings. In human epidermis, p75NTR is mostly confined to the transit-amplifying (TA) sub-population of basal keratinocytes. Brainderived neurotrophic factor (BDNF) or neurotrophin-4 (NT-4), which signals through p75NTR, induces keratinocyte apoptosis, whereas $\beta$-amyloid, a ligand for p75NTR, triggers caspase- 3 activation to a greater extent in p75NTR transfected cells. Moreover, p75NTR co-immunoprecipitates with NRAGE, induces the phosphorylation of $c$-Jun $N$-terminal kinase (JNK) and reduces nuclear factor kappa B (NF- $\kappa$ B) DNA-binding activity. p75NTR also mediates pro-NGF-induced keratinocyte apoptosis through its co-receptor sortilin. Furthermore, BDNF or $\beta$-amyloid cause cell death in TA, but not in keratinocyte stem cells (KSCs) or in p75NTR silenced TA cells. p75NTR is absent in lesional psoriatic skin and p75NTR levels are significantly lower in psoriatic than in normal TA keratinocytes. The rate of apoptosis in psoriatic TA cells is significantly lower than in normal TA cells. BDNF or $\beta$-amyloid fail to induce apoptosis in psoriatic TA cells, and p75NTR retroviral infection restores BDNF- or $\beta$-amyloid-induced apoptosis in psoriatic keratinocytes. These results demonstrate that p75NTR has a pro-apoptotic role in keratinocytes and is involved in the maintenance of epidermal homeostasis.

Cell Death and Differentiation (2011) 18, 948-958; doi:10.1038/cdd.2010.162; published online 10 December 2010

The neurotrophins (NTs) nerve growth factor (NGF), brainderived neurotrophic factor (BDNF), neurotrophin-3 (NT-3), and neurotrophin-4 (NT-4) are a family of secreted growth factors that exert a wide range of functions in the development and maintenance of the nervous system. ${ }^{1}$ The activities of NTs are mediated by two structurally unrelated classes of receptors, the common neurotrophin receptor p75 (p75NTR), ${ }^{2}$ a member of the tumor necrosis factor (TNF)receptor superfamily, ${ }^{3}$ and the Trk family receptors tyrosine kinases. ${ }^{4}$ Although p75NTR binds all NTs with equal low affinity, TrkA preferentially interacts with NGF, TrkB with BDNF and NT-4, and TrkC with NT-3. ${ }^{2}$ Trk-receptor signaling and activities have been well characterized, and it is now widely accepted that the primary role of Trk is the control of neuronal survival and differentiation. ${ }^{5}$ In contrast, the precise role of p75NTR has been slow to emerge. Recent findings suggest that $p 75 N T R$ contributes to different signaling pathways. First, p75NTR is a positive modulator of Trk-mediated functions, in which it functions as a co-receptor that refines Trk affinity and specificity for $\mathrm{NT}^{3}$ On the other hand, p75NTR also controls Trk-independent activities. Numerous studies have demonstrated a pro-apoptotic role of p75NTR in the nervous system. Indeed, the p75NTR cytoplasmic tail contains several potential motifs for interactions with downstream signaling and, similar to other members of the TNF- receptor superfamily, it comprises the so-called 'death domain'. 6 p75NTR can cooperate with many different protein partners and form multimeric receptor complexes to produce a number of cellular responses, including apoptosis. ${ }^{7}$ p75NTR signaling involves modulation of nuclear factor kappa $\mathrm{B}(\mathrm{NF}-\kappa \mathrm{B})$ and the phosphorylation of $c$-Jun $N$-terminal kinase (JNK), as well as increased production of ceramides. ${ }^{8}$ Moreover, the precursor form of NTs pro-NGF binds p75NTR, but not TrkA and is a potent inducer of p75NTR-dependent apoptosis. Sortilin, a $95 \mathrm{kDa}$ member of the $\mathrm{Vps} 10 \mathrm{p}$ domain receptors functions as a co-receptor for p75NTR by binding the pro region of NGF. ${ }^{9}$

Human epidermis is a multilayered epithelium where the principal cell type is the keratinocyte. Proliferation takes place in the basal epidermal layer and differentiation begins as keratinocytes migrate through the suprabasal layers. Keratinocyte stem cells (KSCs) reside in the basal layer, govern the renewal of epidermis, and generate transit-amplifying (TA) cells that terminally differentiate after a number of cell divisions. ${ }^{10}$ Human basal keratinocytes synthesize and secrete biologically active NGF, NT-3, BDNF and NT-4, and express NT receptors. ${ }^{11,12} \mathrm{~K} 252 \mathrm{a}$, an inhibitor of Trk phosphorylation, induces apoptosis in human keratinocytes, indicating that autocrine NGF protects these cells from programmed cell death through its high-affinity receptor. ${ }^{13}$ On the other hand, the role of p75NTR in human keratinocytes

${ }_{1}^{1}$ Institute of Dermatology, School of Biosciences and Biotechnologies, University of Modena and Reggio Emilia, Modena, Italy and ${ }^{2}$ Institute of Dermatology, University of Piemonte Orientale, Novara, Italy

${ }^{*}$ Corresponding author: C Pincelli, Institute of Dermatology, School of Biosciences and Biotechnologies, University of Modena and Reggio Emilia, Via del Pozzo 71, Modena 41100, Italy. Tel: + 39059422 2931; Fax: + 39059422 4271; E-mail: carlo.pincelli@unimore.it

${ }^{3}$ These authors contributed equally to this work

Keywords: p75NTR; keratinocyte; apoptosis; psoriasis

Abbreviations: p75NTR, p75 neurotrophin receptor; NT, neurotrophin; NGF, nerve growth factor; BDNF, brain-derived neurotrophic factor; NT-3, neurotrophin-3; NT-4, neurotrophin-4; KSCs, keratinocyte stem cells; TA, transit amplifying; PM, post mitotic

Received 14.6.10; revised 05.11.10; accepted 08.11.10; Edited by RA Knight; published online 10.12.10 
remains to be elucidated. Considering that the balance between Trk and p75NTR seems to be crucial for cell survival or death, ${ }^{14}$ we wanted to investigate the role of p75NTR in human keratinocytes that express both NT receptors and undergo apoptosis on various stimuli, including the inhibition of Trk. ${ }^{13}$

Hyperproliferation and a distorted differentiation process represent the most prominent features of psoriasis. Psoriasis is an immuno-inflammatory skin disease mediated by the release of Th1 and Th17 T cytokines, which in turn trigger the keratinocyte response. ${ }^{15}$ However, keratinocytes could carry themselves a defect leading to psoriasis formation. ${ }^{16}$ In this regard, apoptosis is consistently reduced in psoriasis, ${ }^{17}$ and psoriatic keratinocytes are abnormally resistant to apoptosis. ${ }^{18}$ Whether p75NTR had a pro-apoptotic role in keratinocyte, we hypothesized that it is also involved in the altered epidermal homeostasis typical of psoriasis.

We present evidence that p75NTR is predominantly expressed in TA cells and induces apoptosis in normal human keratinocytes either alone or in association with sortilin. We also show that, even in the presence of Trk, p75NTR can mediate apoptosis, thus overcoming Trk survival signals. Furthermore, we demonstrate that expression of p75NTR is almost absent in psoriatic lesions.

$\beta$-amyloid or BDNF induces apoptosis in normal, but not in psoriatic TA cells. Finally, p75NTR infection restores susceptibility to apoptosis in psoriatic keratinocytes.

\section{Results}

p75NTR mediates apoptosis in human keratinocytes. Although the presence of p75NTR mRNA in human keratinocytes has been previously reported, ${ }^{11,19}$ its function has never been elucidated. Given the pro-apoptotic activity of p75NTR in most cell systems, we investigated whether p75NTR could mediate cell death also in human keratinocytes. To this purpose, and in order to overcome binding to Trk, we needed a specific ligand for p75NTR, which could trigger Trk-independent functions. $\beta$-amyloid specifically binds p75NTR with an affinity close to that for NT and mediates apoptosis in neurons and 3T3 cells. ${ }^{20}$ When $\beta$-amyloid was provided to human keratinocytes, survival was significantly affected, as compared with control (Figure 1a). In addition, $\beta$-amyloid-induced apoptosis was significantly higher than control, as shown by flow cytometry (subG1 peak, Figure 1b). Caspase- 3 is the executioner caspase responsible for the final step of the apoptotic machinery and its activation is a clear marker of cell death. To confirm p75NTR-mediated apoptosis in human keratinocytes, we evaluated the expression of p75NTR and active caspase- 3 after addition of $\beta$-amyloid. $\beta$-amyloid, but not diluent alone induced the activation of caspase- 3 in p75NTR-positive cells only. In particular, while few p75NTRpositive cells are caspase- 3 negative, all caspase- 3 positive cells express p75NTR (Figure 1c). We have shown previously that human keratinocytes express only the extracellular fragment of TrkB, thus lacking the functional high-affinity signaling domain for BDNF and NT-4. ${ }^{12}$ Therefore, we reasoned that BDNF and NT-4 must perform their activities through p75NTR. Indeed, both BDNF and
NT-4 significantly induced apoptosis in human keratinocytes, in a time-dependent manner, as shown by TUNEL staining (Figure 1d). Moreover, the addition of anti-p75NTR neutralizing antibody prevented BDNF-induced cell death (Figure 1e). To definitely confirm the pro-apoptotic role of p75NTR, we present evidence that both BDNF and $\beta$-amyloid activated caspase-3 to a greater extent in keratinocytes infected with p75NTR retroviral vector, as compared with mock keratinocytes (Figures $1 \mathrm{f}$ and $\mathrm{g}$ ).

p75NTR signals apoptosis in human keratinocytes. Several p75NTR interacting proteins have recently been identified. In particular, NRAGE has been shown to co-localize with p75NTR under physiological conditions and to have a role in p75NTRmediated cell death. ${ }^{21}$ We demonstrated that, in $\beta$-amyloidtreated human keratinocytes, p75NTR and NRAGE immunoprecipitates are more abundant than in keratinocytes treated with diluent alone (Figure 2a). Although the signal transduction involved in p75NTR-mediated apoptosis is still to be completely defined, the critical role of JNK phosphorylation is widely accepted. ${ }^{22}$ We showed that in human keratinocytes, BDNF induced the phosphorylation of only JNK1 (Figure 2b), that, unlike JNK2, is essential for apoptosis induced by death receptors. ${ }^{23}$ On the other hand, the role of NF- $\kappa$ B in p75NTR signal transduction is still controversial. In this study, we demonstrate that BDNF reduced the DNA-binding activity of $\mathrm{NF}-\kappa \mathrm{B}$. Reduction was more pronounced in p75NTR-infected keratinocytes (Figure 2c). This suggests that in human keratinocytes, p75NTR exerts its pro-apoptotic activity also by the inhibition of NF- $\kappa$ B.

p75NTR mediates apoptosis in TA cells. Although p75NTR-induced apoptosis was statistically significant, the low percentage of cells undergoing death remained to be explained. To better clarify this issue, we investigated the expression of p75NTR in human epidermis. We observed that only a sub-population of basal keratinocytes expressed p75NTR, whereas no p75NTR expression was detected in suprabasal layers, as ruled out by the simultaneous staining with keratin 10 and transglutaminase I (Figure 3a). To better determine the sub-population of basal keratinocytes expressing p75NTR, we isolated and characterized KSC and TA cells, as shown previously. ${ }^{24}$ p75NTR mRNA was significantly more expressed in TA cells than in KSC (Figure 3b). Moreover, p75NTR protein was strongly expressed in TA cells and nearly absent in KSC, whereas it was not detectable in post-mitotic (PM) cells (Figure $3 c$ ). Whether p75NTR is predominantly expressed in TA cells, we predicted that apoptosis would occur only in these cells. Indeed, both BDNF and $\beta$-amyloid induced apoptosis in TA cells, whereas they fail to cause cell death in KSC, as shown by the percentage of cells in subG1 peak by flow cytometry (Figure $3 d$ ). To confirm that $p 75 N T R$ is responsible for apoptosis in TA cells, we silenced p75NTR (Figure 3e), and demonstrated that either BDNF or $\beta$-amyloid was not able to induce apoptosis in p75NTR siRNA-treated TA cells (Figure 3f). It is interesting to note that, on treatment with $\beta$-amyloid, the percentage of apoptosis was strikingly higher in TA cells than in the whole keratinocyte population (Figure 1b), as shown by subG1 peak. 
a

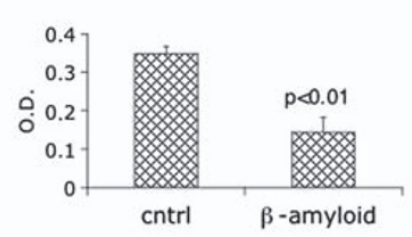

b

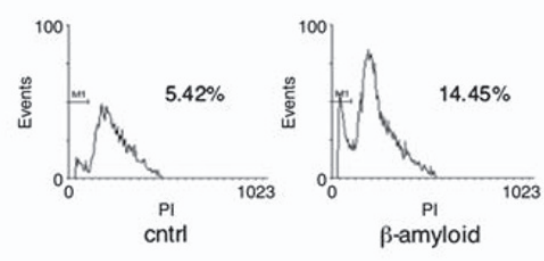

d

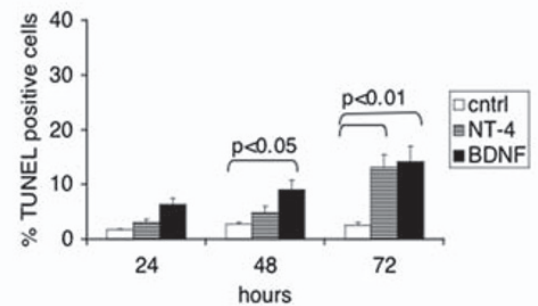

e

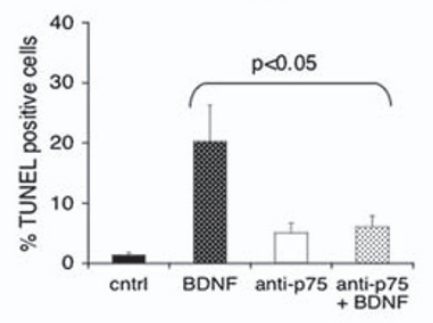

C
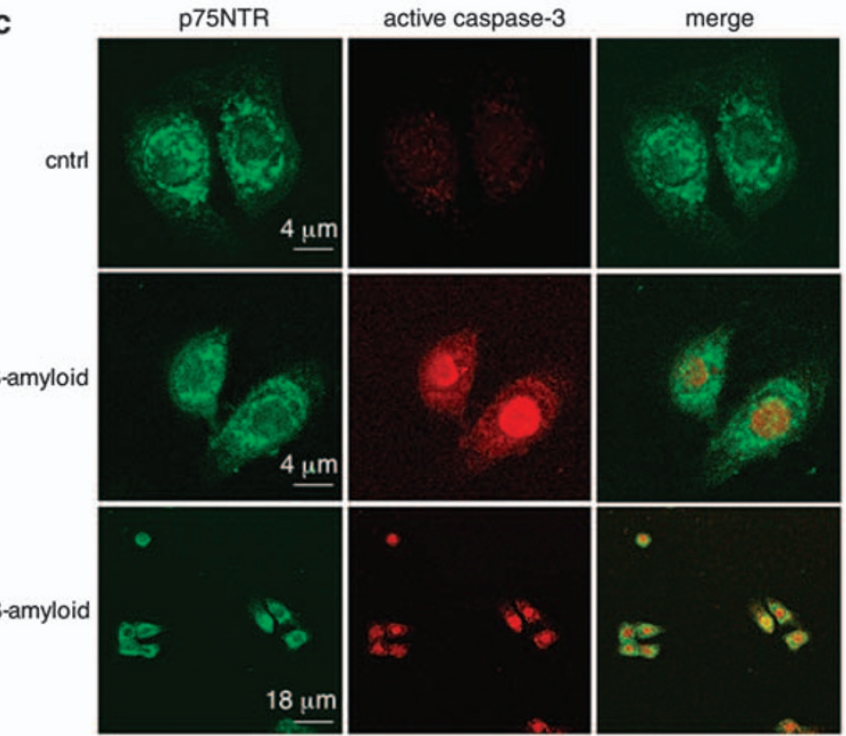

f

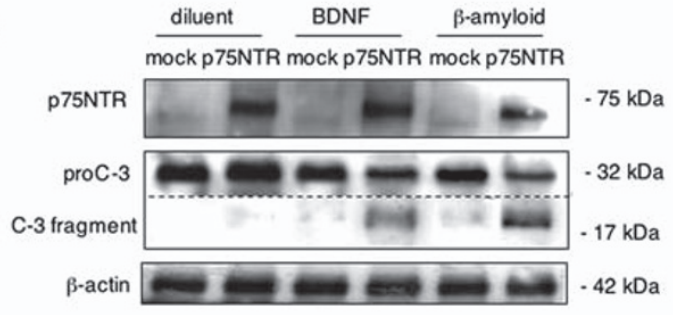

g

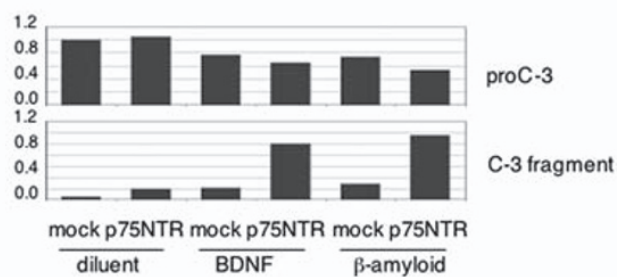

Figure 1 p75NTR modulates apoptosis in normal human keratinocytes in vitro. (a) Confluent keratinocyte cultures, seeded in a 96-well tissue culture plate, were treated with $40 \mu \mathrm{M} \beta$-amyloid or diluent alone. MTT assay was performed after $24 \mathrm{~h}$. Results are expressed as the mean \pm S.D. of three different experiments. Student's $t$-test was used for comparison of the means. (b) Confluent cells were treated as described before, trypsinized at $24 \mathrm{~h}$ and stained with PI. Cells in subG1 peak were analyzed by flow cytometry. (c) Keratinocytes cultures, seeded on chamber slides, were provided with $40 \mu \mathrm{M} \beta$-amyloid or diluent for $24 \mathrm{~h}$. Cells were fixed, double stained in situ with antip75NTR and anti-active caspase-3 antibodies, and analyzed by a Confocal Scanning Laser Microscopy. (d) Confluent keratinocyte cultures were treated with BDNF or NT-4 (100 ng/ml). At 24, 48 and $72 \mathrm{~h}$ cells were fixed and stained in situ with TUNEL. Positive cells were counted as described in Materials and Methods section. (e) Confluent keratinocytes were treated individually or in combination with $100 \mathrm{ng} / \mathrm{ml} \mathrm{BDNF}$ and $50 \mu \mathrm{g}$ per ml of mouse anti-p75NTR neutralizing antibody. After $48 \mathrm{~h}$, cells were stained in situ with TUNEL and positive cells were counted as described in Materials and Methods section. (f) Keratinocytes were transiently infected with p75NTR-LNSN packaging cells or LNSN packaging cells as mock control. Both mock and transfected cells were treated with BDNF $(100 \mathrm{ng} / \mathrm{ml})$ or $\beta$-amyloid $(40 \mu \mathrm{M})$. At $48 \mathrm{~h}$ after treatment, protein extracts from keratinocytes were analyzed by western blotting for p75NTR and caspase-3 expression. $\beta$-actin was used as internal control. (g) Relative intensity of bands on radiograms was quantified by laser scanner densitometry. Values of pro-caspase-3 and caspase-3 fragment are expressed as fold variations compared with mock-diluent keratinocytes

\begin{abstract}
p75NTR mediates pro-NGF-induced keratinocyte apoptosis through its co-receptor sortilin. Because sortilin functions as a co-receptor for p75NTR and mediates apoptosis in other cell settings, ${ }^{9}$ we first evaluated sortilin expression in human keratinocytes. These cells contained levels of sortilin mRNA, which were almost threefold the amount of p75NTR (Figure 4a). Similarly, flow cytometry demonstrated that sortilin protein was expressed in a significantly higher number of cells than p75NTR (Figure $4 b$ ), consistent with the wide variety of functions of
\end{abstract}

this protein. As p75NTR was predominantly expressed in TA cells, we examined the pattern of sortilin expression in the same sub-population of keratinocytes. Consistently with p75NTR, sortilin was expressed mostly in TA cells, whereas KSC contained a slightly higher amount of sortilin than PM cells, both at the mRNA and at the protein level (Figures $4 \mathrm{c}$ and $\mathrm{d}$ ). It has been proposed that pro-NGF binds p75NTR, whereas mature NT binds TrkA. Inhibiting sortilin in cells that normally express p75NTR, suppresses pro-NGFmediated cell death. ${ }^{9}$ As sortilin and p75NTR were both 

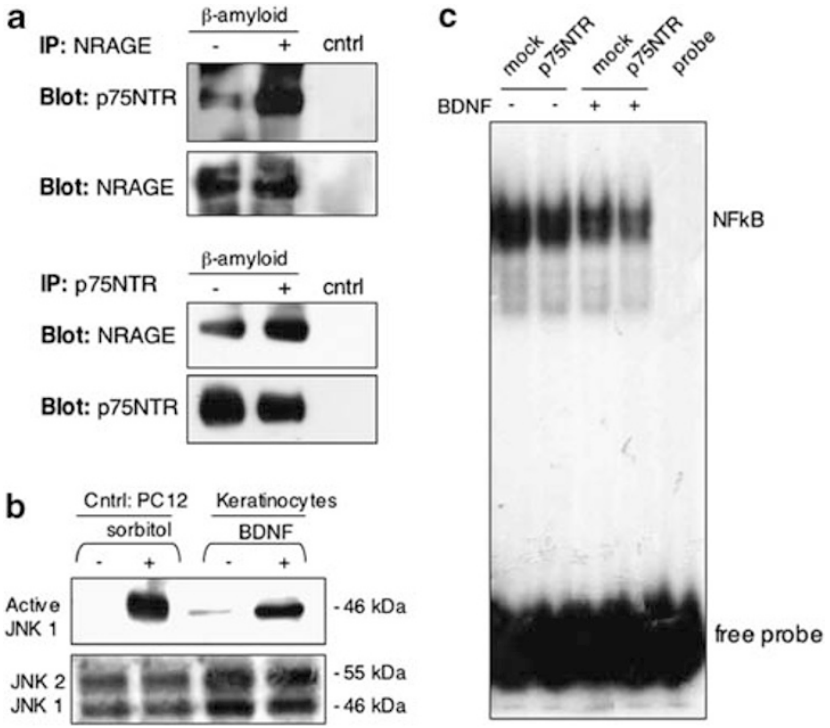

Figure 2 p75NTR induces apoptosis via JNK and NF- $\kappa$ B. (a) Keratinocytes were treated for $24 \mathrm{~h}$ with $\beta$-amyloid $(40 \mu \mathrm{M})$ or diluent. Protein extracts were immunoprecipitated with NRAGE serum and immunoblotted with p75NTR antibody and with NRAGE serum as control. Cell lysates were also immunoprecipitated with p75NTR antibody, immunoblotted with NRAGE serum and with p75NTR antibody as control. (b) Confluent keratinocytes were treated for 5 min with BDNF $(100 \mathrm{ng} / \mathrm{ml})$ and protein extracts were analyzed by western blotting using anti-active JNK1 polyclonal antibody. PC12 cells treated with $0.5 \mathrm{M}$ sorbitol for 5 min were used as positive control. (c) Keratinocytes were infected with p75NTR and treated with with $100 \mathrm{ng} / \mathrm{ml} \mathrm{BDNF}$ or diluent alone for $12 \mathrm{~h}$. Nuclear protein extracts were analyzed by Gel mobility shift assay for NF- $\kappa$ B DNA-binding activity

predominantly expressed in TA cells, we wanted to evaluate the effect of pro-NGF in keratinocytes. Increasing doses of pro-NGF reduced keratinocyte viability (Figure $4 \mathrm{e}$ ). Moreover, co-addition of pro-NGF and the Trk inhibitor k252a decreased the rate of cell survival to a greater extent as compared with pro-NGF or k252a alone (Figure 4f), indicating that simultaneous blockade of Trk signaling and binding of p75NTR is a strong pro-apoptotic stimulus. This was further confirmed by the TUNEL method, which demonstrated a significant rate of apoptosis induced by pro-NGF, which was significantly augmented by the addition of k252a (Figure $4 \mathrm{~g}$ ). To definitely confirm the pro-apoptotic role of p75NTR, we transfected HaCaT keratinocytes with a combination of pcDNA3-p75NTR and pcDNA3-sortilin (Figure 4h). Although transfection alone failed to exert any pro-apoptotic effect, the addition of pro-NGF significantly promoted apoptosis to the same level as the positive control (Figure 4i). Taken together, these results indicate that p75NTR together with sortilin mediates the pro-apoptotic role of pro-NGF in human keratinocytes, even in the presence of Trk.

p75NTR is reduced in lesional psoriatic epidermis. We had previously shown that psoriatic lesions express higher levels of NGF as compared with normal skin, ${ }^{25}$ which accounts for the increased sprouting of p75NTR- and TrkA-positive terminal cutaneous nerves. ${ }^{26}$ In this study, we focused on the expression of p75NTR and Trk receptors in psoriatic keratinocytes. By immunohistochemistry, p75NTR was detected occasionally in few basal cells from nonlesional psoriatic skin, expression being substantially reduced as compared with normal skin. Interestingly, p75NTR protein was completely absent in lesional psoriasis (Figure 5a). To better understand this finding, we evaluated p75NTR expression at the mRNA level. Both northern blot (Figure $5 \mathrm{~b}$ ) and real-time PCR (Figure $5 \mathrm{c}$ ) revealed that p75NTR mRNA was normally expressed in psoriatic epidermis. Yet, western blotting on protein lysates from epidermis (Figure 5d) and flow cytometry (Figure 5e) on suspended cells confirmed the lack of p75NTR protein in psoriatic keratinocytes. On the other hand, TrkA protein levels were higher in non-lesional and lesional psoriatic epidermis than in normal epidermis. Although TrkB was slightly decreased in psoriatic skin, TrkC remained unchanged. Finally, sortilin was slightly increased in lesional psoriatic epidermis (Figure $5 \mathrm{~d}$ ).

Defective p75NTR renders psoriatic TA cells resistant to apoptosis. Because TA cells express the highest levels of p75NTR, we compared its expression in TA cells in normal and psoriatic keratinocytes by flow cytometry. Although no major variations were detected in KSC and PM cells between normal and psoriatic keratinocytes, TA cells from psoriatic keratinocytes presented a four-fold decrease in p75NTR expression as compared with TA from normal cells (Figure 6a). Because TA cells are more prone to cell death than $\mathrm{KSC}^{24}$ and reduced expression of p75NTR in TA cells seems to account for the low levels of p75NTR in psoriasis, we compared the rate of apoptosis in TA and KSC from normal and psoriatic skin. Although the percentage of apoptotic cells was similar in KSC from healthy and diseased skin, TA cells from psoriatic skin were statistically less susceptible to apoptosis than the same cells from normal skin, as shown by propidium iodide staining in situ (Figure 6b). As $\beta$-amyloid and BDNF induce apoptosis in normal keratinocytes, we analyzed their effect on TA cells from psoriatic and normal keratinocytes. Although $\beta$-amyloid or BDNF significantly reduced viability and induced apoptosis (subG1 peak) in TA cells from normal epidermis, they failed to exert any effect on TA cells from psoriatic keratinocytes (Figures $6 \mathrm{c}$ and $\mathrm{d}$ ).

Overexpression of p75NTR restores apoptosis in psoriatic keratinocytes. Because psoriatic epidermis is characterized by defective apoptosis ${ }^{17}$ and reduced p75NTR, we wanted to investigate the function of this receptor in psoriatic keratinocytes. To this purpose, we infected psoriatic keratinocytes with $\mathrm{p} 75 \mathrm{NTR}$ retroviral vector (Figure $7 \mathrm{a}$ ) and treated cells with either $\beta$-amyloid or BDNF. Both stimuli reduced viability in p75NTR-infected psoriatic keratinocytes, but not in mock psoriatic cells (Figure 7b). The difference of $20 \%$ in viability roughly corresponds to the percentage of p75NTR-infected cells (data not shown). Moreover, while infection with p75NTR increased the rate of apoptosis in untreated cells (control), BDNF induced a significantly higher percentage of cells in subG1 peak in p75NTR infected, as compared with either mock keratinocytes or with infected keratinocytes treated with diluent alone (Figure 7c). 

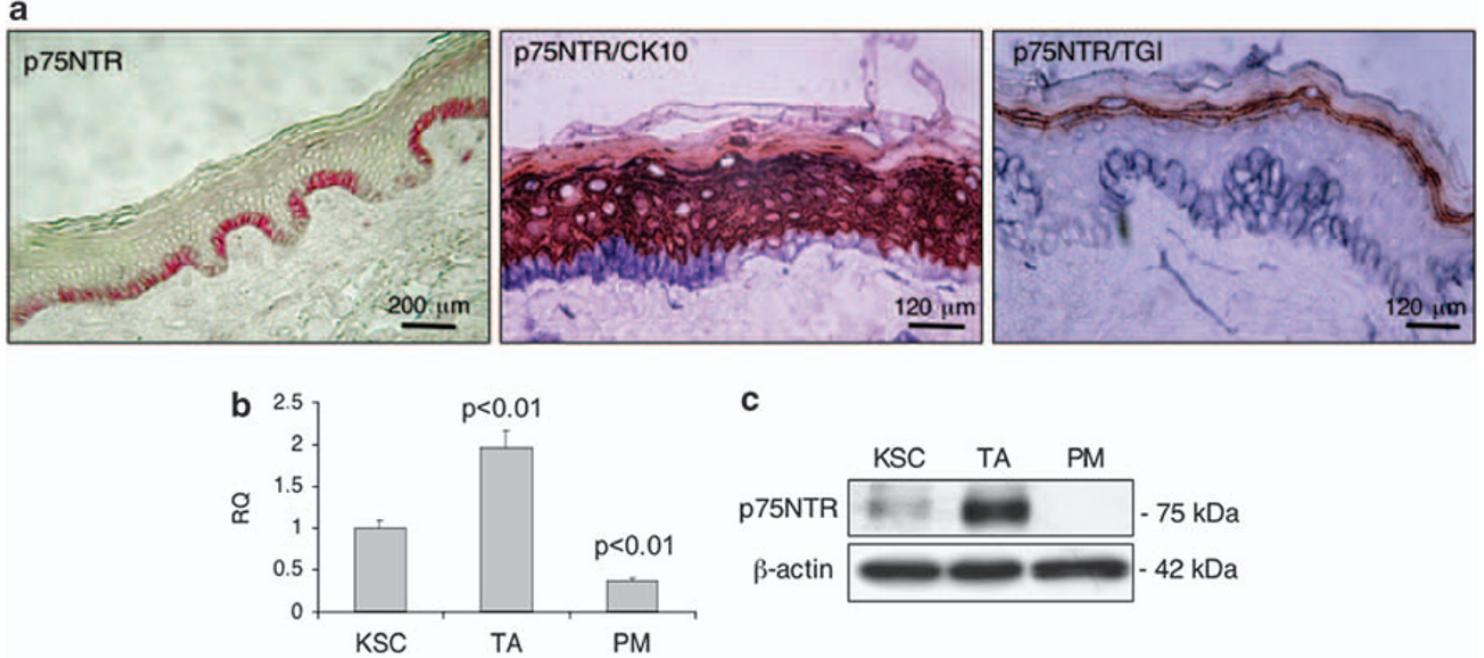

C

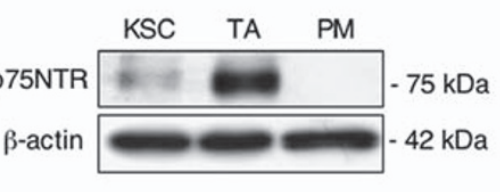

d

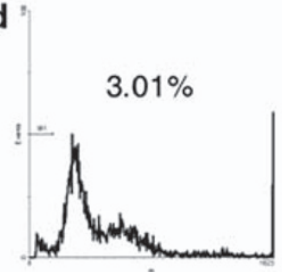

KSC: cntrl

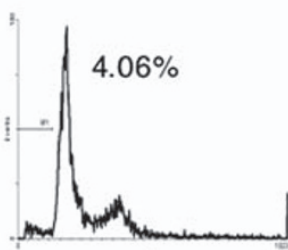

TA: cntrl

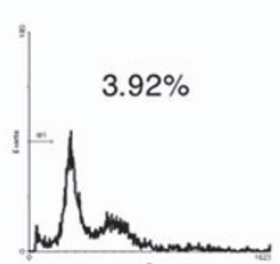

KSC: BDNF

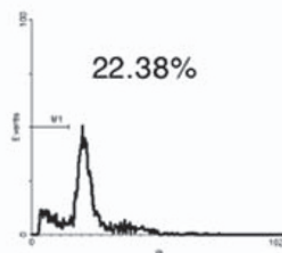

TA: BDNF

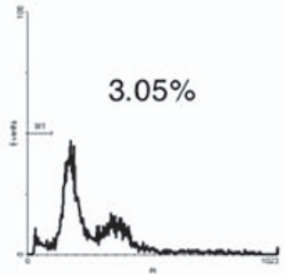

KSC: $\beta$-amyloid

$23.28 \%$

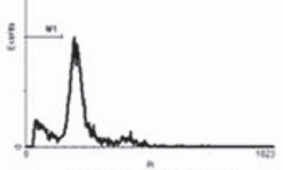

TA: $\beta$-amyloid
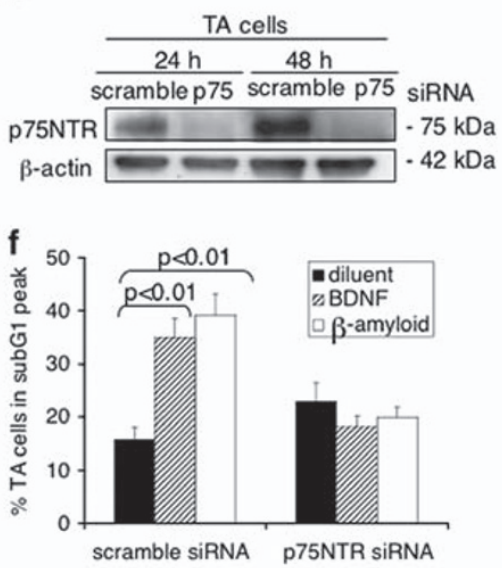

Figure 3 p75NTR-induced apoptosis in TA cells. (a) Cryosections of normal skin were acetone-fixed and stained with anti-p75NTR antibody. Fast red was used as cromogen for p75NTR. Cryosections were double stained with anti-p75NTR and anti-keratin 10 (CK10) antibodies or with anti-p75NTR and transglutaminase type I (Tgasel) antibodies. Fast blue was used as cromogen for p75NTR, whereas carbazol for CK10 and TGasel. (b) Normal human keratinocytes were obtained from neonatal foreskin and separated into three sub-populations on type IV collagen. A real-time PCR was performed on RNA extracts of the three populations by using primers for p75NTR, as described in Materials and Methods section. KSC were used as calibrator. Student's $t$-test was performed between samples and calibrator. (c) Protein extracts from the three populations were separated on $7 \%$ polyacrylamide gels and transferred onto nitrocellulose membrane. Membranes were immunoblotted with anti-p75NTR antibody. $\beta$-actin was used as internal control. (d) KSC and TA cells were treated with either BDNF or $\beta$-amyloid, stained with PI, and analyzed by flow cytometry. (e) TA cells were transiently transfected with $50 \mathrm{nM}$ of p75NTR siRNA, as shown by western blotting. (f) At $48 \mathrm{~h}$ after transfection, both mock and transfected cells were treated with BDNF (100 ng/ml) or $\beta$-amyloid $(40 \mu \mathrm{M})$. SubG1 peak analysis was performed after $24 \mathrm{~h}$

\section{Discussion}

NTs and their receptors are expressed in most human skin cells, constituting a network potentially responsible for multiple functions. ${ }^{12,27}$ In this context, we detected p75NTR in basal keratinocytes, in agreement with previous reports. Although those were mostly incidental observations in studies related to P75NTR expression in cutaneous nerve fibers or during skin pathologies, ${ }^{28}$ our work precisely addresses p75NTR localization in human epidermis. We detected p75NTR in basal, but not in suprabasal keratinocytes, as confirmed by the double staining with keratin 10 and transglutaminase $\mathrm{I}$. This is in general agreement with p75NTR expression in other multilayered epithelial cells, including prostate and esophagus. On the other hand, although in other epithelia p75NTR seems to be evenly distributed, the localization pattern in human epidermis seems to be unique, in that only a sub-population of the germinative basal layer expresses the receptor. We present evidence that p75NTR is almost exclusively expressed in TA cells, with little protein observed in KSC. Although several markers have been proposed, KSC and TA cells are still difficult to be clearly defined. TA cells have been shown to be more susceptible than KSC to apoptosis. ${ }^{29}$ In fact, TA cells express higher levels of pro-apoptotic and lower levels of antiapoptotic markers, as opposed to KSC. ${ }^{24}$ Our finding of p75NTR being predominantly expressed in TA cells seems to be consistent with the pro-apoptotic role of this receptor in human keratinocytes. Keratinocytes also express Trk receptors, ${ }^{11,12}$ and NTs activities strongly depend on the relative expression 
a
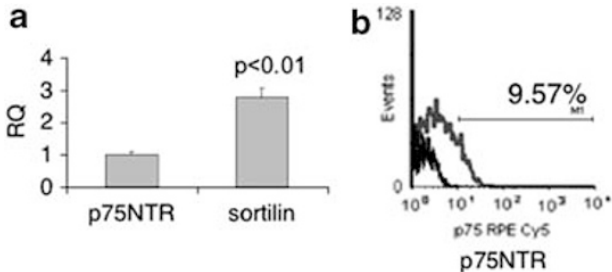

e

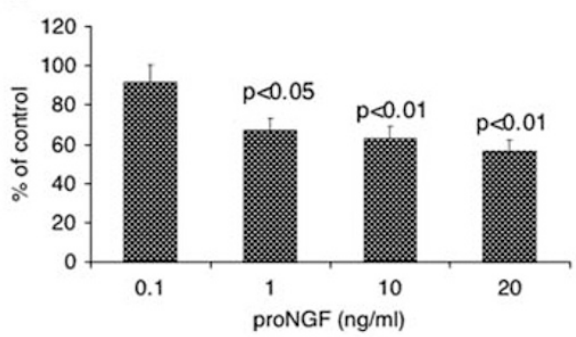

h

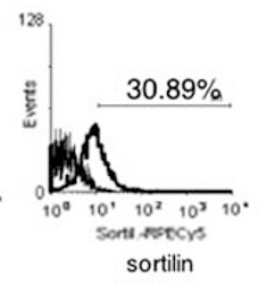

C

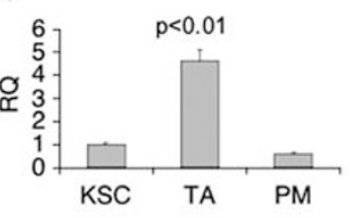

d

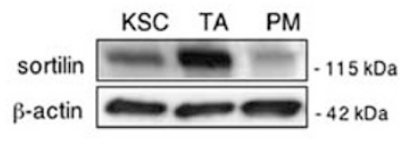

f

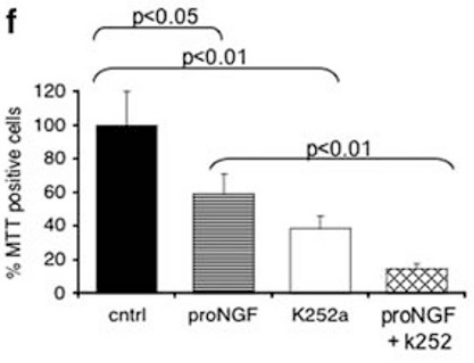

g

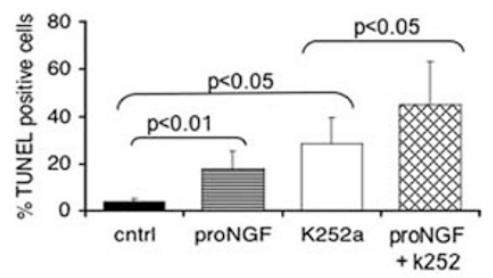

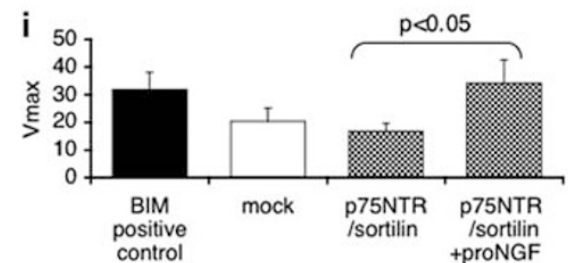

Figure 4 Pro-NGF mediates apoptosis in human keratinocytes through p75NTR and sortilin. (a) Normal human keratinocytes were obtained from neonatal foreskin. A real-time PCR was performed on RNA extracts by using primers for p75NTR and sortilin, as described in Materials and Methods section. p75NTR expression levels were used as calibrator. (b) Keratinocyte cultures were trypsinized and stained with mouse monoclonal anti-p75NTR and polyclonal anti-sortilin antibody. Cells were analyzed by flow cytometry. (c) Normal human keratinocytes were separated into three sub-populations on type IV collagen. Real-time PCR was performed on RNA extracts of the three populations by using primers for sortilin, as described in Materials and Methods section. KSCs were used as calibrator. (d) Protein extracts from the three populations were separated on 7\% polyacrylamide gels and transferred onto nitrocellulose membrane. Membranes were immunoblotted with anti-sortilin antibody. (e) Keratinocyte cultures, seeded in a 96-well tissue culture plate, were treated with $0.1,1,10,20 \mathrm{ng} / \mathrm{ml}$ of pro-NGF. MTT assay was performed after $72 \mathrm{~h}$. (f) Keratinocyte confluent cultures, seeded in a 96-wells tissue culture plate, were treated with $10 \mathrm{ng} / \mathrm{ml}$ of pro-NGF or $200 \mathrm{nM} \mathrm{k252a}$ alone, or in combination. MTT assay was performed after $72 \mathrm{~h}$. (g) Confluent keratinocytes, seeded in a tissue culture slide-flask, were treated as described above. At $72 \mathrm{~h}$, cells were fixed and stained in situ with TUNEL. Positive cells were counted as described in Materials and Methods section. (h) HaCaT cells were transfected with $2 \mu \mathrm{g}$ of pcDNA3-BimEL (positive control) in combination with $2 \mu \mathrm{g}$ of pcDNA3-p75NTR and pcDNA3-sortilin. Transfection was controlled by western blotting using anti-sortilin and anti-p75NTR antibody. (i) After $24 \mathrm{~h}$, cells were treated with $10 \mathrm{ng} / \mathrm{ml}$ of pro-NGF for $24 \mathrm{~h}$. Thereafter, HaCaT cells were lysed and caspase activity was assessed using DEVD-AFC substrate. Data represent the mean \pm S.E. of triplicate determinations

of the two receptors on the target cell population. ${ }^{30}$ When both receptors are expressed, NTs bind to Trk-p75NTR high-affinity complex and mediate survival signals in many cell settings. ${ }^{2}$ In this study, using specific ligands for p75NTR, we were able to induce apoptosis, thus counteracting the survival effects mediated by Trk. Indeed, $\beta$-amyloid specifically binds p75NTR and induces apoptosis only in keratinocytes expressing p75NTR, similarly to $\beta$-amyloid peptide-induced cell death in Alzheimer's neuronal cells ${ }^{31}$ and in neuroblastoma. ${ }^{32}$ Because $\beta$-amyloid is not a physiological ligand for p75NTR in human epidermis, we treated keratinocytes with BDNF or NT-4 that bind p75NTR, in absence of TrkB. In fact, BDNF or NT-4 significantly increase the rate of cell death, and induce a high degree of caspase-3 activation in p75NTR overexpressing keratinocytes. The signaling pathways underlying the p75NTR-dependent apoptotic response involve a number of factors. NRAGE, a p75NTR-interacting protein disrupts p75NTR-TrkA complex, and induces cell death through JNK-dependent pathway, ${ }^{21}$ thus contributing to p75NTRdependent apoptosis. Consistent with these findings, we provide evidence that on binding with a specific ligand, p75NTR interacts with NRAGE and phosphorylates JNK in human keratinocytes. Although JNK activation was mostly demonstrated by overexpressing p75NTR or after serum withdrawal in the nervous system, this study indicates that BDNF, released at the skin level, signals apoptosis, by phosphorylating JNK. p75NTR also activates NF- $\kappa$ B, which is mainly viewed as an antiapoptotic signaling factor. On the other hand, in neonatal rat oligodendrocytes, activation of NF- $\kappa$ B was shown to be associated with apoptosis. Our findings indicate that in human keratinocytes, p75NTR signals apoptosis by the reduction of NF- $\kappa \mathrm{B}$ antiapoptotic function. Taken together, these results suggest that $p 75 N T R$ has its own signaling pathway also in human keratinocytes.

In the neuronal system, pro-NGF binds to p75NTR and its co-receptor sortilin, but not to Trk, whereas mature NTs bind to Trk only, leading to the conclusion that the precursors and the mature NTs elicit opposing responses that is, cell death and survival, respectively. ${ }^{9,33}$ In this study, we show that human keratinocytes express sortilin with a pattern similar to that of p75NTR. Indeed, sortilin is predominantly expressed in TA cells, which are more prone to apoptosis. ${ }^{24}$ This study also shows that pro-NGF induces keratinocyte apoptosis, while the simultaneous inhibition of Trk phosphorylation by k252a elicits 


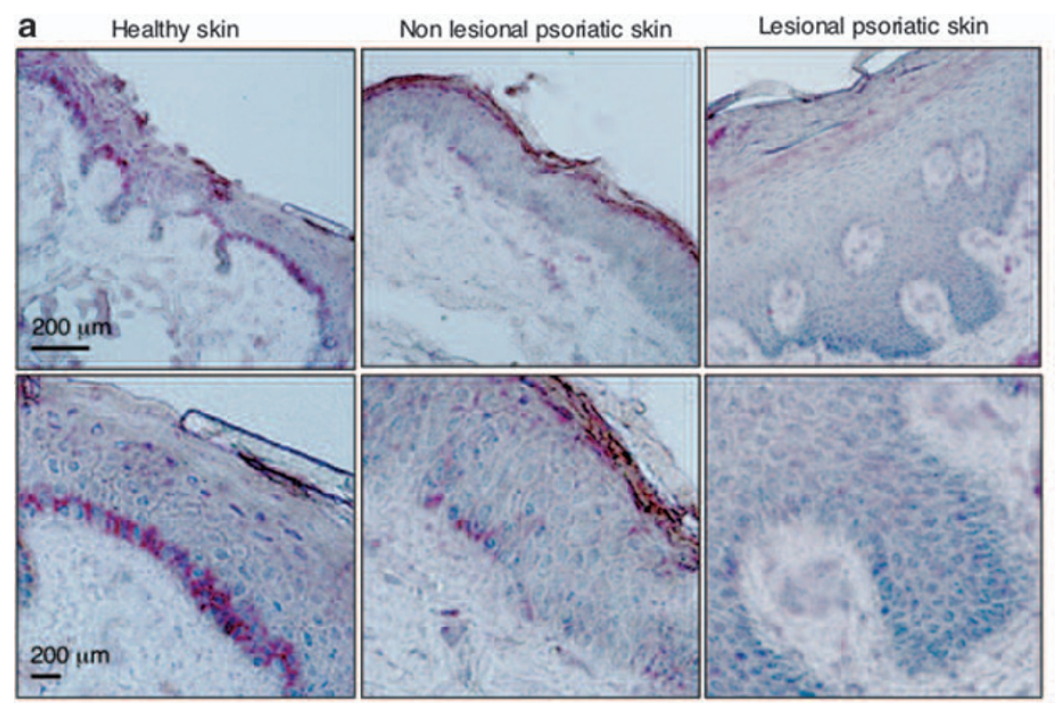

b
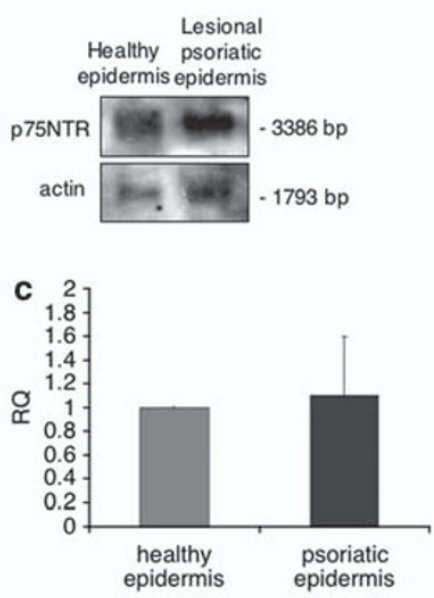
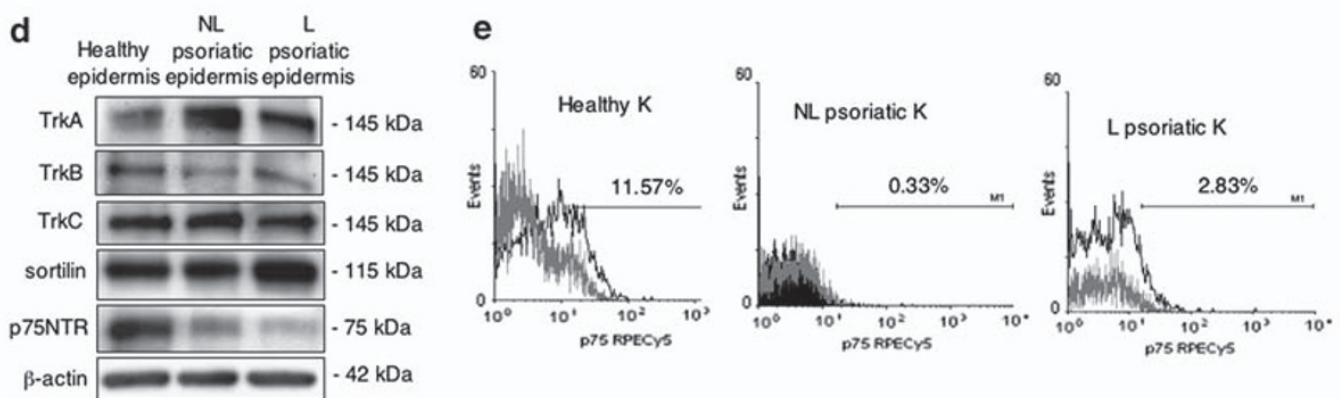

Figure 5 NT-receptor expression in psoriasis. (a) Cryosections of healthy, non-lesional and lesional psoriatic skin were acetone-fixed and stained with anti-p75NTR antibody. Fast red was used as cromogen. (b) mRNA extracts from healthy and psoriatic epidermis were analyzed by northern blot. DIG-labeled probes specific for p75NTR or actin were used. (c) Real-Time PCR was performed on healthy and psoriatic epidermal mRNA, as described in Materials and Methods section. Healthy mRNA was used as calibrator. (d) Protein extracts from healthy, lesional and non-lesional psoriatic epidermis were separated on $7 \%$ polyacrylamide gels and transferred onto nitrocellulose membrane. Membranes were immunoblotted with anti-p75NTR, anti-sortilin, anti-TrkA, anti-TrkB, anti-TrkC and $\beta$-actin antibodies. (e) Keratinocyte extracts from healthy, lesional and non-lesional psoriatic skin were stained with mouse monoclonal anti-p75NTR antibody. Cells, obtained from three different patients, were analyzed by flow cytometry

an additive pro-apoptotic activity, further indicating that the two NT receptors exert opposing effects also in keratinocytes. ${ }^{13}$ Although co-transfection of p75NTR and sortilin per se failed to induce apoptosis, addition of pro-NGF to transfected cells significantly stimulated caspase activation, consistent with the concept that also in keratinocytes, pro-NGF functions as a crosslinker, creating a ternary complex with sortilin and p75NTR. ${ }^{9}$ In substance, we have shown that p75NTR functions as a pro-apoptotic receptor in human keratinocytes either when it is ligated by pro-NGF or by mature NTs. This latter mechanism is at variance with the view that, in the presence of Trk, p75NTR is a facilitator of Trk-mediated survival in the nervous system. A possible explanation relies on the following observations: (1) Although in the neuronal system, high concentrations of mature NTs required to induce even modest levels of apoptosis are considered non-physiological, ${ }^{34}$ in human epidermis, the NT-4, BDNF or other yet unidentified ligands could autocrinally and paracrinally be continuously released and in turn bind p75NTR, thus overcoming Trk functions. (2) Epithelial cells behave differently from neurons, as normal prostate and bladder cells express Trk ${ }^{35,36}$ and still undergo apoptosis via
p75NTR binding. ${ }^{37}$ It has been recently shown that, under certain circumstances and stimuli, a Trk-to-p75NTR molecular switch occurs favoring cell death. ${ }^{38}$

p75NTR is nearly absent in psoriatic keratinocytes that are reportedly resistant to apoptosis. On the other hand, restoring p75NTR levels renders psoriatic keratinocytes again susceptible to cell death. This indicates that p75NTR has a role in epidermal homeostasis and its deficiency accounts for the well-documented resistance of psoriatic keratinocytes to apoptosis. Moreover, p75NTR alteration, coupled with the marked overexpression of NGF and TrkA that mediate survival signals, indicates that the imbalance of NGF receptors underlies the disturbed epidermal homeostasis in psoriasis. Early mathematical models describing cell renewal in psoriasis had demonstrated that the typical psoriatic tissue architecture is based not only on an increased turnover rate in the germinative cell, but also on a defect in cells transiting to the more differentiated state. More recently, Castelijns et al., ${ }^{39}$ using kinetics parameters, have proposed that epidermal abnormalities in psoriasis are due to a defect in the transitamplifying compartment, rather than to a reduction in the cell cycle time. TA cells in psoriasis are thought to be kept in a 
a

\begin{tabular}{|l|c|c|c|}
\hline & KSC & TA & PM \\
\hline Normal k & $2.4 \pm 0.3$ & $23.1 \pm 3.5$ & $3.2 \pm 0.7$ \\
\hline Psoriatic K & $3.2 \pm 0.4$ & $5.9 \pm 0.9$ & $2.2 \pm 0.5$ \\
\hline
\end{tabular}

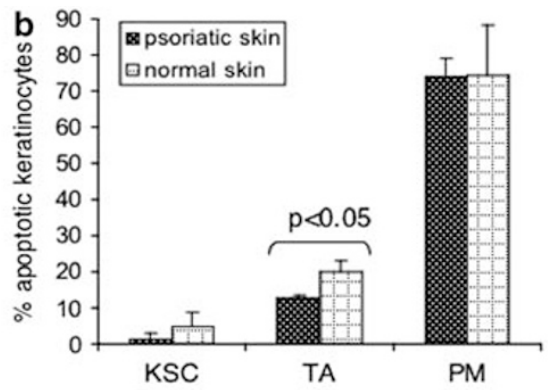

C

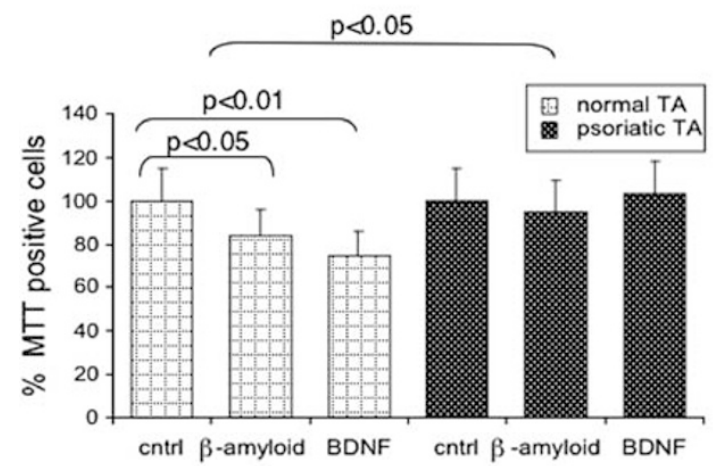

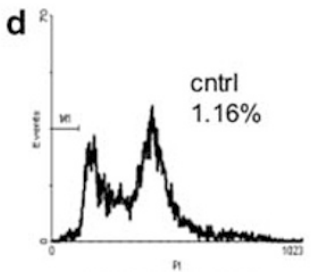
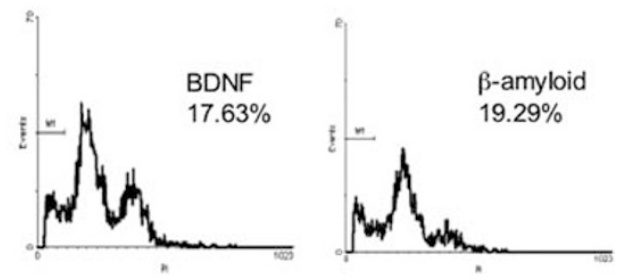

Normal TA cells
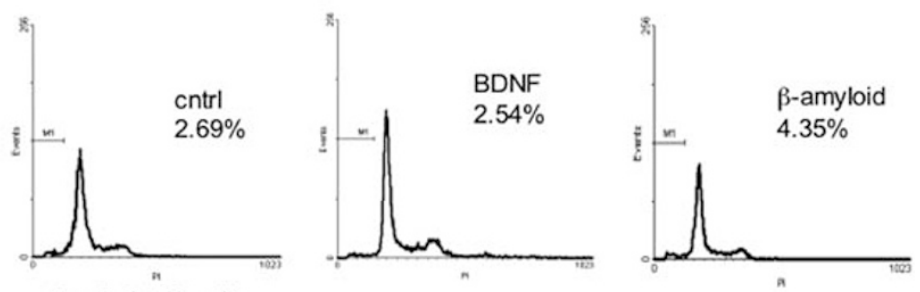

Figure 6 Reduced levels of p75NTR in TA cells are responsible for resistance to apoptosis in psoriatic keratinocytes. (a) Normal and psoriatic human keratinocytes were obtained from skin biopsies and separated into three sub-populations on type IV collagen. Keratinocytes were trypsinized and stained with mouse monoclonal anti-p75NTR and analyzed by flow cytometry. (b) After $48 \mathrm{~h}$, both normal and psoriatic KSC, TA, and PM cells were stained in situ with PI and analyzed by Confocal Scanning Laser Microscopy. Data represent the mean \pm S.E. of triplicate determinations. (c) Keratinocyte cultures obtained from normal and psoriatic biopsies were treated with $40 \mu \mathrm{M}$ $\beta$-amyloid or $100 \mathrm{ng} / \mathrm{ml} \mathrm{BDNF}$. MTT assay was performed after $48 \mathrm{~h}$. (d) Keratinocytes were treated as shown in panel (c) and subG1 peak was evaluated by flow cytometry. Data represent the mean \pm S.E. from three independent experiments

prolonged proliferative state, which would account for an increased number of cell division, with no reduction of cell cycle time. Alternatively, the defect in TA could be due to a lack of differentiation/apoptosis. This has been recently confirmed by in-silico studies simulating psoriasis by altering TA cells. ${ }^{40}$ The inherent malfunction in the behavior of this sub-population is enforced by altered levels of a number of markers in TA from psoriatic lesions as compared with TA from normal skin. ${ }^{41}$ This work demonstrates that the most remarkable reduction in p75NTR expression was detected in TA cells. This finding, together with the lesser susceptibility to apoptosis of psoriatic TA cells, strongly indicates that alteration of TA cells in psoriasis is partly based on a defect in p75NTR. Although there seems to be a general agreement on the prominent role of TA cells in psoriasis, those works were mostly based on computational and expression data. In this study, we show that stimuli that induce apoptosis through p75NTR in TA cells from normal epidermis, fail to do so in psoriatic TA, providing the first functional insight into the defect of this keratinocyte sub-population in the pathogenesis of psoriasis. If p75NTR mRNA is normally expressed in psoriatic keratinocytes, there must be some post-translational alteration leading to the disappearance of the protein, possibly related to a calcium defect in psoriatic keratinocytes. ${ }^{42}$
In conclusion, p75NTR functions as a pro-apoptotic receptor in human keratinocytes and has a crucial role in epidermal homeostasis.

\section{Materials and Methods}

Cell culture. Normal human keratinocytes were obtained from foreskin and cultured in serum-free medium KGM (Clonetics, San Diego, CA, USA) as described. ${ }^{12}$ Freshly keratinocytes were also divided into three populations and plated onto plastic dishes, coated for $2 \mathrm{~h}$ at $37^{\circ} \mathrm{C}$ with type IV collagen $100 \mu \mathrm{g} / \mathrm{ml}$ (Sigma, St. Louis, MO, USA). They were first allowed to adhere to type IV collagen for $5 \mathrm{~min}$, and the non-adherent cells were then transferred to fresh collagen-coated dishes and allowed to attach overnight. Finally, keratinocytes not yet attached after one night were plated onto type IV collagen to obtain a third population. The three keratinocyte populations were characterized on the basis of $\beta_{1}$-integrin levels and colony-forming efficiency, as previously described. ${ }^{24}$ This allowed to obtain a population enriched in KSC, a population consisting of TA cells and a third population of PM cells. Keratinocytes were then cultured in serum-free medium (KGM) and used for further experiments. The spontaneously transformed keratinocyte line HaCaT was kindly provided by Dr. N Fusenig (DKFZ Heidelberg).

Western blotting analysis. Cells or epidermis coming from skin biopsy samples were washed with phosphate-buffered saline (PBS) and lyzed on ice, for Trk, sortilin and JNK detection, in lysis buffer pH 7.4 (50 mM Tris-Hcl, 1\% NP40, $0.25 \%$ sodium deoxycholate, $150 \mathrm{mM} \mathrm{NaCl}, 1 \mathrm{mM} \mathrm{EGTA}, 1 \mathrm{mM} \mathrm{Na}_{3} \mathrm{VO}_{4}, 1 \mathrm{mM} \mathrm{NaF}$ ), for p75NTR detection in lysis buffer pH $7.5(150 \mathrm{mM} \mathrm{NaCl}, 15 \mathrm{mM} \mathrm{MgCl}, 1 \mathrm{mM}$ EGTA, $50 \mathrm{mM}$ Hepes, $10 \%$ Glicerolo, $1 \%$ Triton) or, for caspase-3, with lysis buffer 


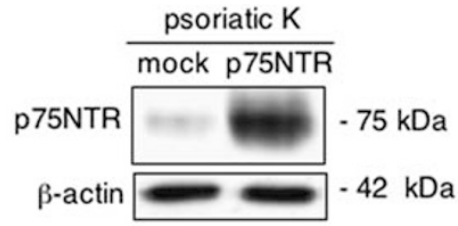

b
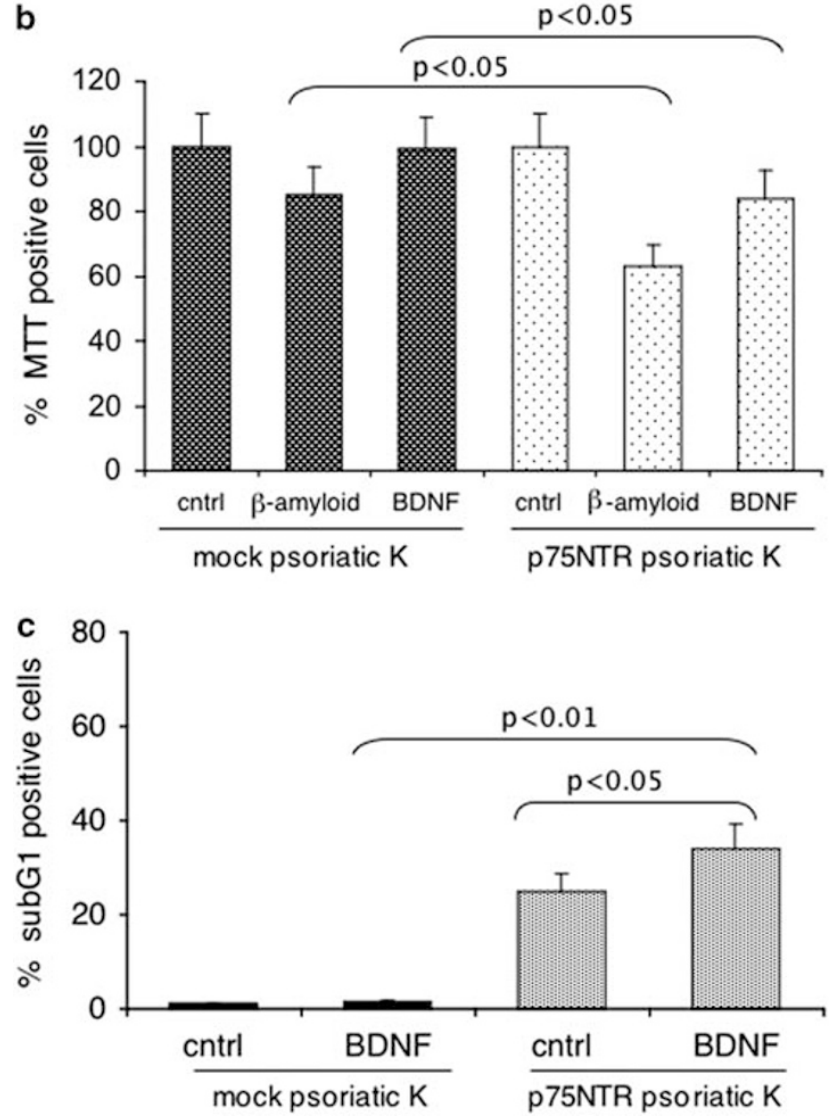

Figure 7 p75NTR infection restores apoptosis susceptibility in psoriatic keratinocytes. (a) Psoriatic keratinocytes were double infected with mock or p75NTR retroviral vector and infection controlled by western blotting. (b) At $48 \mathrm{~h}$ after infection, cells were treated with $40 \mu \mathrm{M} \beta$-amyloid or $100 \mathrm{ng} / \mathrm{ml} \mathrm{BDNF}$ or diluent. MTT assay was performed after $48 \mathrm{~h}$. Data represent the mean \pm S.E. of triplicate determinations. (c) Mock and p75NTR infected keratinocytes were provided $100 \mathrm{ng} / \mathrm{ml} \mathrm{BDNF}$ or diluent and analyzed by flow cytometry after $48 \mathrm{~h}$. Data represent the mean \pm S.E. of triplicate determinations

pH 6.8 (62.5 mM Tris-HCl, 2\% SDS, 10\% glycerol, 50 mM DTT, 0.01\% bromophenol blue) containing protease inhibitors, as described previously. ${ }^{12}$ A measure of $20 \mu \mathrm{g}$ of total protein were analyzed under reducing conditions for sortilin and JNK on $7 \%$ polyacrylamide gels and blotted onto nitrocellulose membranes. To verify equal loading of total proteins in all lanes, the membranes were stained with Ponceau Red. The blots were blocked for $2 \mathrm{~h}$ in blocking buffer (PBS buffer, $\mathrm{pH}$ 7.4 , with $0.2 \%$ Tween 20 and $5 \%$ non-fat milk) and incubated overnight at $4{ }^{\circ} \mathrm{C}$ with anti-p75NTR mouse monoclonal (1:1000; Upstate, Lake Placid, NY, USA), anti-TrkA rabbit polyclonal (1:1000; Upstate), anti-TrkB rabbit polyclonal (1:750; Upstate), anti-TrkC goat polyclonal (1:750; Upstate), anti-sortilin mouse monoclonal antibody (1:250; BD Biosciences Pharmingen, San Diego, CA, USA), anti-active JNK (1:5000; Promega, Madison, WI, USA), anti-caspase-3 (1: 1000; Cell Signaling Technology, Boston, MA, USA) or with anti- $\beta$-actin mouse monoclonal antibody (1:5000; Sigma) as a control. Then membranes were washed in PBS/Tween 20, incubated with peroxidase-conjugated goat anti-rabbit antibody, anti-mouse antibody (1:3000; Biorad, Hercules, CA, USA) or donkey anti-goat antibody (1:1000; Santa Cruz Biotechonology Inc., Santa Cruz, CA, USA) for $45 \mathrm{~min}$ at room temperature, washed, and developed using the ECL chemiluminescent detection system (Amersham Biosciences UK Limited, Little Chalfont Buckinghamshire, England).

Immunoprecipitation. Human keratinocytes were treated with or without $40 \mu \mathrm{M} \beta$-amyloid. After $24 \mathrm{~h}$, cells were harvested with RIPA buffer $(10 \mathrm{mM}$ Tris, $\mathrm{pH}$ $8.0 ; 150 \mathrm{mM} \mathrm{NaCl} ; 1 \%$ Nonidet P-40, $0.5 \%$ deoxycholate; $0.1 \%$ SDS) containing protease inhibitors. Nuclei were removed by centrifugation (11 000 r.p.m. for $3 \mathrm{~min}$ ). Monoclonal antibody anti-p75NTR (Upstate) or polyclonal serum against NRAGE (kindly provided from professor P.A. Barker) was bound to sepharose beads for $1 \mathrm{~h}$ at $4{ }^{\circ} \mathrm{C}$ under rotation. Thereafter, pre-cleared lysates were conjugated to sepharose beads-antibody complex or to sapharose beads alone as control, overnight at $4^{\circ} \mathrm{C}$ under rotation. Immunocomplexes were washed with Port Buffer $(10 \mathrm{mM}$ Tris- $\mathrm{HCl}$, pH 8.5; $150 \mathrm{mM} \mathrm{NaCl} ; 0.1 \%$ Renex 30; $0.01 \% \mathrm{BSA} ; 2.5 \% \mathrm{NaN}_{3}$ ) six times and with PT Buffer (10 mM Tris-HCl, pH 8.5; $150 \mathrm{mM} \mathrm{NaCl;} 0.5 \%$ Tween 20; $2.5 \% \mathrm{NaN}_{3}$ ) three times. Samples were eluted with $1 \times$ Laemnli sample buffer for $5^{\prime}$ at $90^{\circ} \mathrm{C}$ and western blotting for p75NTR or NRAGE was performed as previously described.

Transfection of HaCaT cells. For p75NTR and sortilin transient transfection, cells were seeded in 6-well plates $\left(5 \times 10^{5}\right.$ cells/well) and in 96-well tissue culture plate $\left(4 \times 10^{4} \mathrm{cells} /\right.$ well) in antibiotic-free medium. HaCaT cells were double transfected using Lipofectamine Plus reagent (Invitrogen Corporation, Carlsbad, CA, USA) with $2 \mu \mathrm{g} / \mathrm{well}$ (in 6-well plates) or $0.15 \mu \mathrm{g} / \mathrm{well}$ (in 96-well plates) of pcDNA3-BimEL or pcDNA3-p75NTR or pcDNA3-sortilin overnight in Opti-MEM medium (Invitrogen Corporation). Thereafter, cells were treated with various stimuli for further experiments and p75NTR or sortilin protein level was detected by western blotting, as described below.

siRNA transfection of TA cells. About $7 \times 10^{4} \mathrm{TA}$ cells/well were plated on 6 -well plates in penicillin/streptomycin-free medium. After $24 \mathrm{~h}$, cells were transfected with 50 or $100 \mathrm{nM}$ of p75NTRsiRNA (Dharmacon Inc., Lafayette, CO, USA) or scrambled RNAi as mock control, combined with Lipofectamin 2000 and Opti-MEM (both from Invitrogen Corporation) as datasheet suggests. Cells were transfected twice and used for FACS analysis. p75NTR protein level was detected by western blotting, as described below.

Infection of normal and psoriatic keratinocytes. Cells $\left(10^{6}\right)$ from normal or psoriatic biopsies were plated on $75 \mathrm{~cm}^{2}$ flask over a feeder-layer of mitomycin C-treated $3 T 3$ fibroblasts $\left(7 \times 10^{5}\right.$ cells for $75 \mathrm{~cm}^{2}$ flask) and mitomycin C-treated p75NTR-LNSN packaging cells $\left(3.5 \times 10^{5}\right.$ for 75 flask $)$ or mitomycin C-treated LNSN packaging cells (kindly provided from professor F Mavilio) with medium for keratinocytes ${ }^{11}$ without EGF. After $48 \mathrm{~h}, \mathrm{EGF}$ was added to the cultures. At $24 \mathrm{~h}$ after infection cells were plated in KGM for MTT, PI or western blot analysis.

Real-time PCR. RNA from cells separated into the three populations or from total keratinocytes or from healthy or psoriatic epidermis was extracted using TRI Reagent method performed as described by Sigma. To verify the quality of the RNA, we ran an agarose minigel in RNase-free conditions. Quantitative real-time PCR was performed with an ABI 7500 (Applied Biosystems, Foster City, CA, USA) for p75NTR and sortilin. As an internal control, housekeeping gene $\beta$-actin mRNA expression was measured in a separated tube. $\mathrm{H}_{2} \mathrm{O}$ RNAse-free was used as a negative control. We performed three independent experiments, and each one was analysed in a triplicate PCR-reaction. Thereafter, $1 \mu \mathrm{g}$ of RNA was subjected to retro-transcription and amplification in a $50 \mu \mathrm{l}$ reaction mixture using the One-Step RT-PCR Master Mix Reagents kit (Applied Biosystems). For p75NTR, sortilin and $\beta$-actin amplification were used Pre-Developed TaqMan Assay Reagents (MGB probes were FAM or VIC dye labeled, Applied Biosystems). Thermal cycling conditions for one-step RT-PCR were: initial reverse transcription at $48^{\circ} \mathrm{C}$ for $30 \mathrm{~min}$, then DNA polymerase activation at $95^{\circ} \mathrm{C}$ for $10 \mathrm{~min}$, followed by 40 cycles of denaturation at $95^{\circ} \mathrm{C}$ for $15 \mathrm{~s}$, annealing/extension at $60^{\circ} \mathrm{C}$ for $1 \mathrm{~min}$. Data from each sample were compared with a calibrator, using the Sequence Detection Software Version 1.2.3 according to the Relative Quantification Study method (Applied Biosystems). Results were obtained as the mean from three independent experiments. Double-sided Student's $t$-test was performed between samples and calibrator.

Immunohistochemistry. For double staining, cryosections $(4 \mu \mathrm{m})$ of normal human skin were acetone-fixed, rehydrated in PBS. Quenching of the endogenous 
peroxidase activity was obtained by treatment with $3 \% \mathrm{H}_{2} \mathrm{O}_{2}$ in PBS. Samples were incubated either with mouse anti-transglutaminase type I (1:10; Biomedical Technologies Inc., Stoughton, MA, USA) or with mouse anti-cytokeratin 10 antibody (1:50; Dako, Glostrup, Denmark) for $1 \mathrm{~h}$, then with secondary antibody anti-mouse biotinylated (1:3000; Dako) for $45 \mathrm{~min}$ and with a streptavidin-biotin peroxidase complex for $30 \mathrm{~min}$. The reaction products were visualized with amino-methylenecarbazole. Double staining was continued by incubating the slides with $1 \%$ goat serum. Then the slides were incubated with mouse anti-p75NTR antibody $(1: 250$ Lab Vision Corporation, Neomarkers, Fremont, CA, USA) for $1 \mathrm{~h}$ and, after three washes of $5 \mathrm{~min}$ in PBS, slides were incubated with secondary antibody anti-mouse (1:20; Dako) for $45 \mathrm{~min}$ at room temperature, followed by incubation with antimouse alkaline phosphatase complex for $30 \mathrm{~min}$ (1:20; Dako). After three washes of $5 \mathrm{~min}$ in PBS, the slides were stained with Fast blue (Sigma). Negative controls were obtained by omitting primary antibody.

For single staining, cryosections $(4 \mu \mathrm{m})$ of normal, non-lesional and lesional psoriatic human skin were acetone-fixed $(10 \mathrm{~min})$, rehydrated in PBS. The slides were incubated with mouse anti-p75NTR antibody (1:250; Lab Vision Corporation) for $1 \mathrm{~h}$ and, after three washes of $5 \mathrm{~min}$ in PBS, incubated with secondary antibody anti-mouse (1:20; Dako) for $45 \mathrm{~min}$ at room temperature, followed by incubation with anti-mouse alkaline phosphatase complex for $30 \mathrm{~min}$ (1:20; Dako). After three washes of 5 min in PBS, the slides were stained with New fucsin (Sigma).

Confocal immunofluorescence. For double staining, keratinocyte cultures were washed in PBS buffer and fixed in situ in 4\% paraformaldehyde for $20 \mathrm{~min}$ and air-dried. After a rehydratation in PBS, cells were permeabilized for $10 \mathrm{~min}$ with $0.5 \%$ Tryton $\mathrm{X}-100$ in $0.1 \%$ sodium citrate, treated for $5 \mathrm{~min}$ with $50 \mathrm{mM} \mathrm{NH}_{4} \mathrm{Cl}$ and incubated with $1 \%$ bovine albumin serum for $20 \mathrm{~min}$. Thereafter, cells were incubated for $1 \mathrm{~h}$ with the mouse monoclonal anti-caspase-3 active antibody (1:100; R \& D Systems, Minneapolis, MN, USA) and for $1 \mathrm{~h}$ with RPE Cy5conjugated anti-mouse (1:100; Dako). Thereafter, keratinocytes were washed in PBS, labeled with a mouse anti-p75NTR antibody (1:250, Lab Vision Corporation) for $1 \mathrm{~h}$ and with FITC-conjugated anti-mouse antibody (1:100; Dako) for $45 \mathrm{~min}$. Fluorescent specimens were analyzed by a Confocal Scanning Laser Microscopy (Leica TCS SP2).

MTT assay. Keratinocytes or transfected $\mathrm{HaCaT}$ were plated in 96-well tissue culture plate (8000 cells/well). At $72 \mathrm{~h}$ after seeding, cells were treated with $40 \mu \mathrm{M}$ $\beta$-amyloid ${ }^{25-35}$ (Bachem, Bubendorf, Switzerland) or $100 \mathrm{ng} / \mathrm{ml} \mathrm{BDNF}$ or $100 \mathrm{ng} / \mathrm{ml}$ NT-4 or different doses of pro-NGF (kindly provided from B. Hempstead) for 24, 48 and $72 \mathrm{~h}$. Proliferative cells were detected by incubating with MTT (Sigma-Aldrich) solution at $37^{\circ} \mathrm{C}$ for $4 \mathrm{~h}$. They were solubilizated with DMSO and the formazan dye formation was evaluated by scanning multiwell spectrophotometer at $540 \mathrm{~nm}$. The results are expressed as optical density units (OD) or as viability percentage respect of control. Results are calculated as the mean \pm S.D. of three different experiments. Student's $t$-test was used for comparison of the means.

Cell death analysis by flow cytometry. At $72 \mathrm{~h}$ after seeding, cells were treated with $40 \mu \mathrm{M} \beta$-amyloid or $100 \mathrm{ng} / \mathrm{ml}$ BDNF. After 24 or $48 \mathrm{~h}$, cells were trypsinized and resuspended $\left(5 \times 10^{5}\right.$ cells) in 1-ml hypotonic fluorochrome solution: $50 \mu \mathrm{g} / \mathrm{ml}$ propidium iodide containing $0.1 \%$ sodium citrate and $0.5 \%$ Tryton X-100 (Sigma). After $15 \mathrm{~min}$, cells were analyzed using an Epics XL flow cytometer (Coulter Electronics Inc., Hialeah, FL, USA). Apoptosis was detected by evaluating the reduced fluorescence of the DNA-binding dye PI in the apoptotic nuclei.

TUNEL assay. Cells after treatment were fixed in situ in paraformaldehyde (4\% in PBS) and air-dried. The slides were stained with the 'In situ cell death detection kit' (Roche Diagnostics, Basel, Switzerland) as recommended by the manufacturer. Fluorescent specimens were analyzed by confocal scanning laser microscopy (Leica TCS SP2, Leica microsystems, Wetzlar, Germany) in conjunction with a conventional optical microscope (Leica DM IRBE, Leica). Results are calculated as the mean \pm S.D. of three different experiments. Student's $t$-test was used for comparison of the means.

Detection of apoptotic cells by confocal microscopy. Cell were seeded on glass coverslips coated with poly-L-lysine $100 \mathrm{mg} / \mathrm{ml}$ for $5 \mathrm{~min}$, fixed in methanol: water $(80: 20)$ for $5 \mathrm{~min}$, washed in PBS and subsequently stained with propidium iodide (Sigma, $5 \mu \mathrm{g} / \mathrm{ml}$ in PBS) for $5 \mathrm{~min}$. Coverslips are examined by laser-scanning confocal microscopy (Leica TCS-SP2) to identify apoptotic nuclei. Nuclei were scored and more than 400 nuclei were counted for each sample.
The results are expressed as percentage of the number of apoptotic nuclei over the total number of nuclei examined.

FACS analysis. Keratinocytes were washed in PBS and incubated with mouse biotin-coniugated anti-p75NTR $\left(20 \mu \mathrm{l} / 1 \times 10^{6}\right.$ cells, BD Biosciences Pharmingen) or rabbit polyclonal anti-sortilin antibody $(1: 2000$; kind gift from Claus M. Petersen, Aarhus University, Denmark) for $20 \mathrm{~min}$ at $4^{\circ} \mathrm{C}$. For sortilin, after a brief washing in PBS, the cells were incubated with the biotinylated anti-rabbit antibody 1:500 (Dako, Glostrup, Denmark) for 20 min on ice. For both staining, the incubation with antibodies was followed by incubation with streptavidin/RPE-Cy5 1:50 (Dako) for 20 min on ice. After washing, cells were analyzed using an Epics XL flow cytometer (Beckman Coulter, Inc, Brea, CA, USA)

Caspase activity measurements. The caspase-3-like protease activity in cell lysates was measured using a fluorometric substrate Ac-DEVD-AFC (Alexis Corporation, San Diego, CA, USA), which was dissolved in dimethyl sulfoxide and stored as a $10 \mathrm{mM}$ solution at $-20^{\circ} \mathrm{C}$. HaCaT cells were collected, washed in cold PBS, and lysed at $4^{\circ} \mathrm{C}$ in buffer A (50 mM HEPES, pH 7.5, $150 \mathrm{mM} \mathrm{NaCl}, 20 \mathrm{mM}$ EDTA, $1 \mathrm{mM}$ phenylmethylsulfonyl fluoride, $10 \mu \mathrm{g} / \mathrm{ml}$ leupeptin, $1 \mu \mathrm{g} / \mathrm{ml}$ aprotinin, and $0.3 \%$ Nonidet P-40). Homogenates were centrifuged (13000 r.p.m., $10 \mathrm{~min}$ ), and the protein concentrations of the supernatants were determined using a Bradford protein assay kit (Bio-Rad). Equal amounts of supernatants (normalized for protein content) were mixed in wells of 96 -well plates in a $100 \mu \mathrm{l}$ final volume, in buffer $\mathrm{B}$ (50 mM HEPES, pH 7.4, $100 \mathrm{mM} \mathrm{NaCl}, 1 \mathrm{mM}$ EDTA, $10 \%$ sucrose, $0.5 \%$ CHAPS, $5 \mathrm{mM}$ dithiothreitol, and $100 \mu \mathrm{M}$ Ac-DEVD-AFC substrate (caspase-3/7). Substrate cleavage was monitored continuously by spectrofluorometry, in kinetic mode, using Fluorolite 1000 (Dynatech Laboratories Inc., Chantilly, VA, USA). Data are reported as relative fluorescence units of product produced per min per $10 \mu \mathrm{g}$ of total protein.

Northern blot. Northern blot was performed using DIG Northern Starter Kit (Roche). Briefly, total cellular epidermal mRNA taken from biopsy samples of patient with or without psoriasis was isolated with $1 \mathrm{ml}$ of TRI Reagent performed as described by Sigma. p75NTR DNA in pCEP4 vector was linearized at restriction sites downstream of the cloned insert and purified. PCR of p75NTR vector using T7 RNA polymerase promoter sequences (FW:5'-CTCATCCCTGTCTATTGCTCCA-3'; REV:5'-TAATACGACTCACTATAGGAGCTGGAGCATCGGTTGTC-3') was performed using Expand High Fidelity PCR System (Roche). A measure of $1 \mu \mathrm{g}$ of p75NTR DNA template was labeled with T7 RNA polymerase for $1 \mathrm{~h}$ at $42^{\circ} \mathrm{C}$, after that DNAse I was added for $15 \mathrm{~min}$ at $37^{\circ} \mathrm{C}$, to remove DNA template, as manufacture's instructions. Yield of DIG-labeled p75NTR RNA was determined by comparing it to DIG-labeled actin RNA as control $(10 \mathrm{ng} / \mu \mathrm{l})$. In all, $2 \mu \mathrm{g}$ of total RNA from patients was loaded in MOPS/formaldehyde gel. RNA was blotted over nylon membrane, positively charged, by capillary transfer overnight. The RNA was fixed by short-wave UV exposure and RNA hybridization was performed using DIG-labeled p75NTR probe at $68^{\circ} \mathrm{C}$ overnight with gentle agitation. Membrane was incubated with anti-digoxigenin$\mathrm{AP}$, Fab fragments (1:10000 in blocking solution) for $30 \mathrm{~min}$ at room temperature. Membrane was washed, equilibrated for $5 \mathrm{~min}$ and covered with CDP-Star ready-touse solution for $5 \mathrm{~min}$ at $20^{\circ} \mathrm{C}$ and signal imaging was developed. To perform actin control, membrane was stripped and hybridized with DIG-labeled actin RNA probe and detection was performed as described before.

Gel mobility shift assay. Nuclear proteins were isolated from the cellular pellets. Samples were suspended with hypotonic buffer $(1.5 \mathrm{mM} \mathrm{MgCl} 2,0.2 \mathrm{mM}$ PMSF, $1 \mathrm{mM}$ DTT, $10 \mathrm{mM} \mathrm{KCl}, 10 \mathrm{mM}$ HEPES, pH 7.9) for $15 \mathrm{~min}$. Proteins were centrifuged, then the pellets were washed with hypotonic buffer and centrifuged. Supernatants were discarded and pellets were suspended in low-salt buffer (25\% glycerol, $1.5 \mathrm{mM} \mathrm{MgCl}_{2}, 0.2 \mathrm{mM}$ EDTA, $0.2 \mathrm{mM}$ PMSF, $1 \mathrm{mM}$ DTT, $20 \mathrm{mM}$ $\mathrm{KCl}, 20 \mathrm{mM}$ HEPES, pH 7.9). Nuclear proteins were released by adding high-salt buffer (25\% glycerol, $1.5 \mathrm{mM} \mathrm{MgCl}$, $0.2 \mathrm{mM}$ EDTA, $0.2 \mathrm{mM}$ PMSF, $1 \mathrm{mM}$ DTT, $1.2 \mathrm{M} \mathrm{KCl}, 20 \mathrm{mM}$ HEPES, $\mathrm{pH}$ 7.9). Samples were incubated on ice for $30 \mathrm{~min}$, centrifuged and supernatants were collected and stored at $-70^{\circ} \mathrm{C}$.

Double-stranded oligonucleotides for the NF- $\kappa$ B-binding site were obtained from Santa Cruz Biotechnology and labeled with $\left[\gamma_{-}{ }^{32} \mathrm{P}\right]$ ATP (Perkin-Elmer, Waltham, MA, USA) and T4 polynucleotide kinase (Promega). The labeled oligonucleotides were separated on a SDS-PAGE gel and eluted out of the gel in distilled $\mathrm{H}_{2} \mathrm{O}$ $\left(4^{\circ} \mathrm{C}\right.$, overnight) and the activity of labeled probe was counted.

Total of $5 \mu \mathrm{g}$ of nuclear proteins were used in each reaction. Extracts were incubated with the radiolabeled probe in binding buffer $(4 \mathrm{mM}$ Tris- $\mathrm{HCl}, 12 \mathrm{mM}$ 
HEPES at pH 7.9, $60 \mathrm{mM} \mathrm{KCl}, 0.5 \mathrm{mM}$ EDTA, $1 \mathrm{mM}$ dithiothreitol, and $12 \%$ glycerol) for $25 \mathrm{~min}$ at room temperature. Non-specific binding was blocked by $2 \mu \mathrm{g}$ of poly $(\mathrm{dl}-\mathrm{dC})$ : poly(dl-dC) (Sigma). After incubation, samples were fractionated on a $4 \%$ polyacrylamide gel in $0.25 \times$ Tris-borate-EDTA at $4^{\circ} \mathrm{C}$. Following electrophoresis, the gel was dried and autoradiographed.

\section{Conflict of interest}

The authors declare no conflict of interest.

Acknowledgements. This work was supported by a grant from Ministry of Instruction, University and Research PRIN 2003061751_004. We wish to thank Chiarella Bozzo for technical advise and scientifical support.

1. Dechant G. Molecular interactions between neurotrophin receptors. Cell Tissue Res 2001; 305: 229-238.

2. Chao MV, Bothwell M. Neurotrophins: to cleave or not to cleave. Neuron 2002; 33: 9-12.

3. Chen Y, Zeng J, Cen L, Chen Y, Wang X, Yao G et al. Multiple roles of the p75 neurotrophin receptor in the nervous system. J Intl Med Res 2009; 37: 281-288.

4. Barbacid M. The Trk family of neurotrophin receptors. J Neurobiol 1994; 25: 1386-1403.

5. Lei L, Parada LF. Transcriptional regulation of Trk family neurotrophin receptors. Cell $\mathrm{Mol}$ Life Sci 2007; 64: 522-532.

6. Chapman BS, Kuntz ID. Modeled structure of the $75-\mathrm{kDa}$ neurotrophin receptor Protein Sci 1995; 4: 1696-1707.

7. Gentry JJ, Baker PA, Carter BD. The p75 neurotrophin receptor: multiple interections and numerous functions. Prog Brain Res 2004; 146: 25-39.

8. Blöchl A, Blöchl R. A cell-biological model of p75NTR signaling. J Neurochem 2007; 102 289-305.

9. Nykjaer A, Lee R, Teng KK, Jansen P, Madsen P, Nielsen MS et al. Sortilin is essential for proNGF-induced neuronal cell death. Nature 2004; 427: 843-848.

10. Jones $\mathrm{PH}$, Simons BD, Watt FM. Sic transit gloria: farewell to the epidermal transit amplifying cell? Cell Stem Cell 2007; 1: 371-381 . Review.

11. Pincelli $C$, Sevignani $C$, Manfredini $R$, Grande A, Fantini $F$, Bracci-Laudiero $L$ et al. Expression and function of nerve growth factor and nerve growth factor receptor on cultured keratinocytes. J Invest Dermatol 1994; 103: 13-18.

12. Marconi A, Terracina M, Fila C, Franchi J, Bonté F, Romagnoli G et al. Expression and function of neurotrophins and their receptors in cultured human keratinocytes. $J$ Invest Dermatol 2003; 121: 1515-1521. Erratum in: J Invest Dermatol 2004; 123: 803.

13. Pincelli $C$, Yaar M. Nerve growth factor: its significance in cutaneous biology. J Invest Dermatol Symp Proc 1997; 2: 31-36.

14. Yoon SO, Casaccia-Bonnefil $P$, Carter B, Chao MV. Competitive signaling between TrkA and p75 nerve growth factor receptors determines cell survival. J Neurosci 1998; 18: 3273-3281.

15. Nickoloff BJ, Qin JZ, Nestle FO. Immunopathogenesis of psoriasis. Clin Rev Allergy Immunol 2007; 33: 45-56

16. Tschachler E. Psoriasis: the epidermal component Clin Dermatol 2007; 25: 589-595.

17. Heenen M, Simonart T. Apoptosis in psoriatic epidermis. J Cutan Pathol 2008; 35: 346.

18. Wrone-Smith T, Johnson T, Nelson B, Boise LH, Thompson CB, Núñez G et al. Discordant expression of Bcl-x and Bcl-2 by keratinocytes in vitro and psoriatic keratinocytes in vivo. Am J Pathol 1995; 146: 1079-1088.

19. Di Marco E, Mathor M, Bondanza S, Cutuli N, Marchisio PC, Cancedda R et al. Nerve growth factor binds to normal human keratinocytes through high and low affinity receptors and stimulates their growth by a novel autocrine loop. J Biol Chem 1993; 268 22838-22846.

20. Yaar M, Zhai S, Pilch PF, Doyle SM, Eisenhauer PB, Fine RE et al. Binding of beta-amyloid to the 75 neurotrophin receptor induces apoptosis. A possible mechanism for Alzheimer's disease. J Clin Invest 1997; 100: 2333-2340.
21. Salehi AH, Xanthoudakis S, Barker PA. NRAGE, a p75 neurotrophin receptor-interacting protein, induces caspase activation and cell death through a JNK-dependent mitochondria pathway. J Biol Chem 2002; 277: 48043-48050.

22. Costantini C, Rossi F, Formaggio E, Bernardoni R, Cecconi D, Della-Bianca V. Characterization of the signaling pathway downstream p75 neurotrophin receptor involved in beta-amyloid peptide-dependent cell death. J Mol Neurosci 2005; 25: 141-156.

23. Liu J, Minemoto Y, Lin A. c-Jun N-terminal protein kinase 1 (JNK1), but not JNK2, is essential for tumor necrosis factor alpha-induced c-Jun kinase activation and apoptosis. Mol Cell Biol 2004; 24: 10844-10856.

24. Tiberio R, Marconi A, Fila C, Fumelli C, Pignatti M, Krajewski S et al. Keratinocytes enriched for stem cells are protected from anoikis via an integrin signaling pathway in a Bcl-2 dependent manner. FEBS Lett 2002; 524: 139-144.

25. Fantini F, Magnoni C, Bracci-Laudiero L, Pincelli CTE. Nerve growth factor is increased in psoriatic skin. J Invest Dermatol 1995; 105: 854-855.

26. Raychaudhuri SP, Raychaudhuri SK. Role of NGF and neurogenic inflammation in the pathogenesis of psoriasis. Prog Brain Res 2004; 146: 433-437.

27. Botchkarev VA, Yaar M, Peters EM, Raychaudhuri SP, Botchkareva NV, Marconi A et al. Neurotrophins in skin biology and pathology. J Invest Dermatol 2006; 126 1719-1727.

28. Yiangou Y, Facer P, Sinicropi DV, Boucher TJ, Bennett DL, McMahon SB et al. Molecular forms of NGF in human and rat neuropathic tissues: decreased NGF precursor-like immunoreactivity in human diabetic skin. J Perpher Nerv System 2002; 7: 190-197.

29. Marconi A, Dallaglio K, Lotti R, Vaschieri C, Truzzi F, Fantini $F$ et al. Survivin identifies keratinocyte stem cells and is downregulated by anti- $\beta 1$ integrin during anoikis. Stem Cells 2007; 25: 149-155.

30. Lu B, Pang PT, Woo NH. The yin and yang of neurotrophin action. Nat Rev Neurosci 2005; 6: 603-614.

31. Hashimoto $Y$, Kaneko $Y$, Tsukamoto E, Frankowski H, Kouyama K, Kita $Y$ et al. Molecular characterization of neurohybrid cell death induced by Alzheimer's amyloid-beta peptides via p75NTR/PLAIDD. J Neurochem 2004; 90: 549-558.

32. Perini G, Della-Bianca V, Politi V, Della Valle G, Dal-Pra I, Rossi F et al. Role of p75 neurotrophin receptor in the neurotoxicity by beta-amyloid peptides and synergistic effect of inflammatory cytokines. J Exp Med 2002; 195: 907-918. Erratum in: J Exp Med 2002; 195 1231.

33. Teng HK, Teng KK, Lee R, Wright S, Tevar S, Almeida RD et al. ProBDNF induces neuronal apoptosis via activation of a receptor complex of p75NTR and sortilin. $J$ Neurosci 2005; 25: 5455-5463.

34. Kim JY, Roh JK, Lee SK, Chung CK. Neurotrophin receptor immunoreactivity in severe cerebral cortical dysplasia. Epilepsia 2002; 43 (Suppl 5): 220-226.

35. Guate JL, Fernández N, Lanzas JM, Escaf S, Vega JA. Expression of p75(LNGFR) and Trk neurotrophin receptors in normal and neoplastic human prostate. B J U Int 1999; 84 495-502.

36. Murray E, Malley SE, Qiao LY, Hu VY, Vizzard MA. Cyclophosphamide induced cystitis alters neurotrophin and receptor tyrosine kinase expression in pelvic ganglia and bladder $J$ Urol 2004; 172: 2434-2439.

37. Quann EJ, Khwaja F, Zavitz KH, Djakiew D. The aryl propionic acid R-flurbiprofen selectively induces p75NTR-dependent decreased survival of prostate tumor cells. Cance Res 2007; 67: 3254-3262.

38. Costantini C, Weindruch R, Della Valle G, Puglielli L. A TrkA-to-p75NTR molecular switch activates amyloid beta-peptide generation during aging. Biochem J 2005; 391: 59-67.

39. Castelijns FA, Gerritsen MJ, van Erp PE, van de Kerkhof PC. Cell-kinetic evidence for increased recruitment of cycling epidermal cells in psoriasis: the ratio of histone and Ki-67 antigen expression is constant. Dermatology 2000; 201: 105-110.

40. Grabe N, Neuber K. Simulating psoriasis by altering transit amplifying cells. Bioinformatics 2007; 23: 1309-1131.

41. Franssen ME, Zeeuwen PL, Vierwinden G, van de Kerkhof PC, Schalkwijk J, van Erp PE. Phenotypical and functional differences in germinative subpopulations derived from normal and psoriatic epidermis. J Invest Dermatol 2005; 124: 373-383.

42. McKenzie RC, Oda Y, Szepietowski JC, Behne MJ, Mauro T. Defective cyclic guanosine monophosphate-gated calcium channels and the pathogenesis of psoriasis. Acta Derm Venereol 2003; 83: 414-418. 